Do pictures 'tell' a thousand words in lectures? How lecturers vocalise photographs in their presentations

Madeline J Hallewell ${ }^{1} \&$ Natasa Lackovic ${ }^{2}$

${ }^{1}$ Corresponding author: University of Nottingham, Nottingham, NG7 2RD, UK.

M.Hallewell@nottingham.ac.uk.

${ }^{2}$ Educational Research, Lancaster University, LA1 4YD, Lancaster, UK.

n.lackovic@lancaster.ac.uk

(forthcoming article) 


\title{
Do pictures 'tell' a thousand words in lectures? How lecturers vocalise photographs in their presentations
}

\begin{abstract}
This article explores how 145 photographs collected from 20 PowerPoint lectures in undergraduate psychology at 16 UK universities were integrated with lecturers' speech. Little is currently known about how lecturers refer to the distinct types of photographs included in their presentations. Findings show that only 48 photographs (33\%) included in presentation slides were referred to explicitly by exploring their features to make a point related to the lecture content, with only 14 of these used to invite student questioning. Most photographs (97 or 67\%) represent a case of 'unprobed representations', that is, either 'embedded' in the talk as 'illustrations' of the speech topic or not referred to at all. A taxonomy of uses that lecturers made of the photographs in their slideshows was created through adapting a Peircean semiotic analysis of the photograph-speech interaction. The implications in terms of lecturer and student engagement with the photographic material are discussed, arguing the case for more Critical Semiotic Exploration of photographs in HE practice.
\end{abstract}

Keywords: lecture; images, Higher Education; PowerPoint; semiotics 


\section{Introduction}

Photographs have featured in lectures for as long as it has been possible to take and display them (Nelson, 2000). Therefore, it is surprising that the manner of how the photographs are spoken about in lectures has been given little if any attention in Higher Education (HE) research and studies of lectures. Indeed, Bateman (2014, p.252) identifies the need to address how 'spoken language and visual presentation (using for example, tools such as Power point, Keynote, Prezi to accompany speech)' work together. The photographs referred to here can be defined as anything captured by the camera, depicting phenomena, objects, situations/activities and actors.

Photographs might appear in lectures because viewing them is an integral aspect of the lecture's message (e.g. photographs of cells in microbiology, or famous paintings in art history (Bligh \& Lorenz, 2010)). Within these contexts, lecturers would talk about the photograph to deconstruct specific meanings relevant to teaching goals (Pozzer \& Roth, 2003). It is here suggested that if a photograph features in a lecture in any discipline, it is then a legitimate learning resource which could be explored towards pedagogical goals. However, it is not argued that every single photograph should be used in this way.

Commonly used slideware, such as PowerPoint, affords and may even encourage the inclusion of photographs. Yet, many PowerPoint critics have argued that photographs are often included merely to 'decorate' slides (Gabriel, 2008; Kjeldsen, 2006) or perhaps for the satisfaction of what is popularly and uncritically called 'visual' learners (Exley \& Dennick, 2004). There are still few studies exploring photographs in lecturers' speech and/or slide presentations. However, Pozzer and Roth's (2003) taxonomy of photographs' functions in relation to textual content in science textbooks 
has been utilised to explore their role in slides in HE (Slykhuis, Wiebe, \& Annetta, 2005). A taxonomy of four photograph functions - decorative, illustrative, explanatory and complementary (Pozzer \& Roth, 2003) - was applied in relation to accompanying captions and the slide body text.

Another study that tackles photographs in slide presentations is Rowley-Jolivet's (2002) exploration of the functions of 2000 visual representations in 90 papers presented at a conference, covering the fields of geology, medicine and physics. Photographs of phenomena were classed as Figurative I, 'devoid of scientific content, serve, in popularisations, to attract the exoteric reader by showing the human side of science’ (Rowley-Jolivet, 2002, p. 29), in contrast to Figurative II, such as X-ray (=Roentgen signs) and scans. However the definition of Figurative I is problematic, since it is exactly the meaning assigned to photographs in learning situations that can link them to scientific concepts (Lackovic, 2014). Moreover, Cantor (2000) suggests that reading an x-ray does involve "the human side" of science in order to 'read' the sign and establish diagnosis.

The extent to which lecturers - in disciplines where photographs are not prominent resources in the curriculum - explore photographs in lectures is a vague and under-researched area. This study contributes to addressing this gap by adopting semiotic approaches for exploring what uses are actually made of photographs in lecturers' talk.

\section{A semiotic approach to lecturing}

Semiotics is a broad discipline, or approach, concerned with meaning-making processes. Its main unit of analysis is the 'sign', that is, any entity that makes meaning in society representing and referring to something else (Fiske, 2010), e.g. road signs, 
language, maths or chemistry symbols, music notation, and photographs. Semiotics provides tools to help understand how photographs make meaning. Such understanding starts from considering a sign's structural affordances and expands into a critical questioning of its relationship to and interactions with society and context.

Figure 1 illustrates a semiotic account of the viewer's meaning-making process at the moment of looking at a photograph (Lackovic, 2014; Nellhaus, 1998). It shows a triangular framework of meaning-making processes (Object-RepresentamenInterpretant) that is related to the socio-cultural and contextual meanings circulating among the author, viewer and the photograph's materiality itself (Rose, 2012).

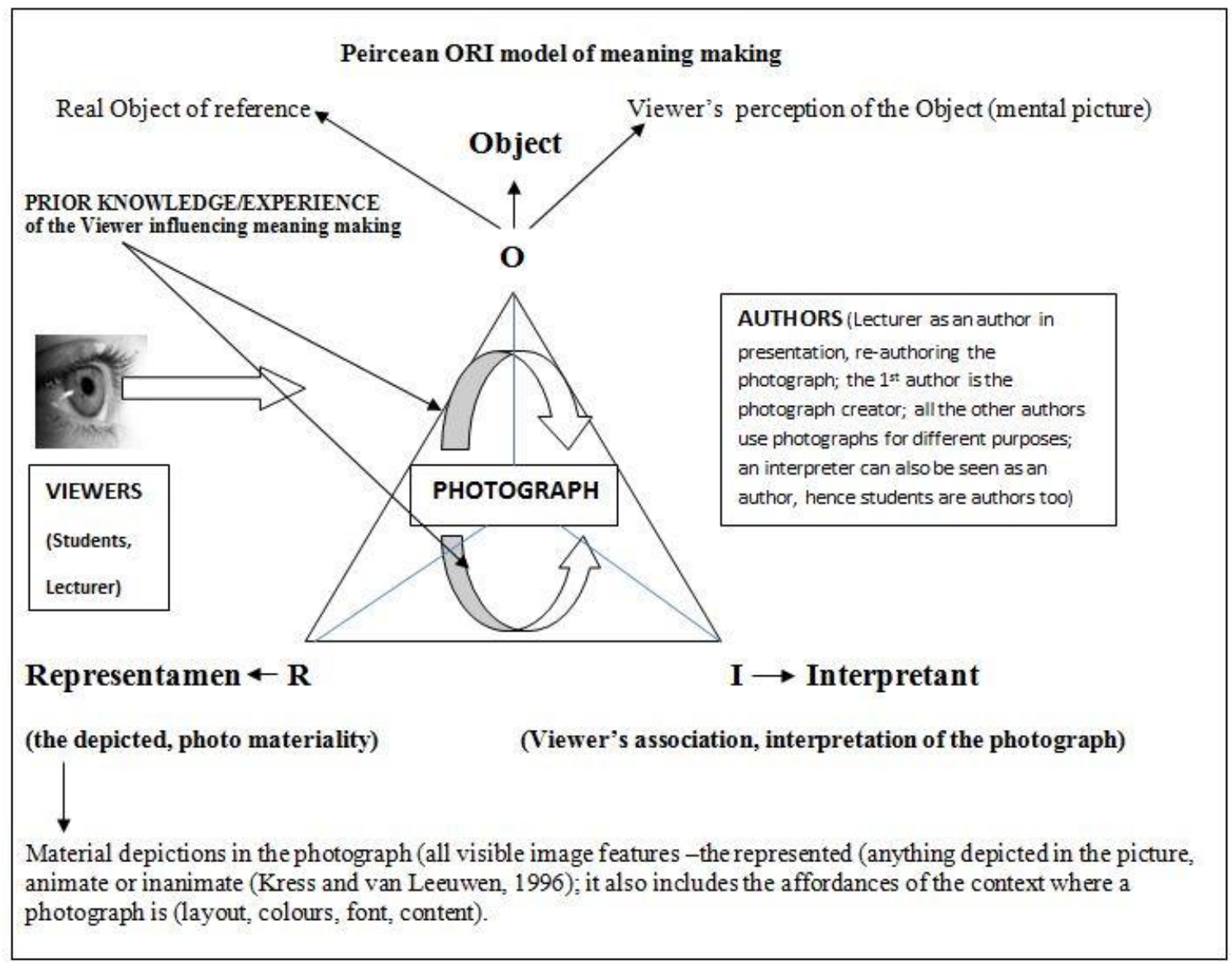

Figure 1: A model of meaning-making from photographs in lectures building on the Peircean semiotic triad adapted from Nellhaus (1998) and Lackovic (2014). 
The photograph refers to an Object $^{1}$ of reference (Nellhaus, 1998), something the photograph represents. Representamen is the photograph itself and its materiality and depictive qualities, namely what details viewers can identify and recognise in the photograph. Interpretant is how viewers interpret the details seen (how we establish the relationship between the Representamen(s) and Object). This semiosis does not happen in a vacuum, it happens in a context, under socio-cultural circumstances, each sign being subject to constant re-semiosis and re-authoring by its users.

In Figure 1 when a viewer-student- looks at a photograph, the meaning of the seen is derived at an intersection of Representamen, Interpretant and Object (Nellhaus, 1998). These processes happen simultaneously. This 'blink of the eye' simultaneity and speed obscures meaning-making structural subtleties. The meaning-making of the seen is influenced by the immediate context and our prior knowledge and experience, how we associate the seen with our existing cognitive schemata (Ausubel, 1978; PozzerArdenghi \& Roth, 2005). The semiotic, and therefore learning potential of a photographic sign in a lecture lies in the invitation to students to critically explore that photograph - that is, its Object-Representatmen-Interpretant's relationship and meanings - within a given context and in relation to their lives, the society and culture.

A semiotic approach to lectures means that lecturers consider and take advantage of interrogating the structure of photographic meaning-making (Figure 1), formulating questions that tackle various levels of meaning (examples listed later), in accordance with the lecture content and discipline. Components of the meaning- making process include the human agency and socio-cultural conditioning surrounding the

\footnotetext{
${ }^{1}$ It must be noted that Peircean semiotics is far more complex, making many more distinctions, which are beyond the scope of this paper.
} 
photograph: who it is viewed by, presented by, created by, where and why is it produced, who are the agents who have intentions and power (Hodge and Kress, 1988)?

Eye tracking research has revealed that students pay more attention to the photographs made highly relevant (i.e. those that are spoken about) and quickly ignore those deemed to be added 'simply for the sake of spicing up the text' (Slykhuis et al., 2005). Therefore, the lecturer can prompt students to interpret the photograph and not only glance at it, providing sufficient time to think more about it and its meaning (Sless, 1981).

Of course not every photograph needs to be talked about; it must be acknowledged that some photographs are best positioned as metaphorical, illustrative or entertaining add-ons. However, engaging critically with the visual world we inhabit can help with the unpacking of visual 'myths' (Barthes, 1977, 1981), which are systematically constructed and repeated ideas attached to visuals (e.g. femininity, masculinity, ethnicity, schooling, love, beauty etc.) that are evoked when viewing them. It supports a critical attitude towards any images encountered in everyday life such as those that proliferate the media (Apple, 2013). Indeed 'social semiotics' (Hodge \& Kress, 1988) calls for considering the motives behind the production and consumption of signs: basically how they are made to operate in society. Photographs are produced in relation to particular socio-cultural circumstances and purposes, and selected by lecturers to make a particular point in a lecture; this is useful to be discussed and acknowledged if there is to be critical engagement with photographs used in educational contexts.

Critical graphicacy, also connected to semiotics, calls for serious engagement with photographs and all communication 'devices' that carry meanings (verbal texts, graphs, drawings, photographs). The approach argues that using an image as an 
exploratory learning tool in its own right can support the development of students' critical graphicacy (Roth, Pozzer-Ardenghi, \& Han, 2005) through students applying critical semiotic analysis to 'different forms representing' (Roth et al., 2005, p.23). This can be achieved through questioning the represented from various angles (provenance, purpose, time (now, past, future) etc.). This helps students go beyond a singular view point and approach a phenomenon from various vantage points. Whitley (2013) has noted that students are more than capable of interpreting signs in this way, if only they are given the opportunity and motivation to do so.

In addition, explanations with and via photographs may support students in understanding any point made in lecture better. Any student - but especially students who attend lectures in the language other than their native one - are found likely to experience difficulty in lecture comprehension (Mulligan \& Kirkpatrick, 2000). This difficulty might be alleviated by asking questions and acknowledging students' opinions, with reference to photographs.

Much more can be said about the need to and processes of engaging critically with visual representations from various vantage points such as visual culture, critical pedagogy, deconstruction and multimodality. In sum, when including photographs in their slides, lecturers have much potential to invite critical and semiotic engagement with them from students, but not with all photographs, all the time. Aware of this potential and the research gaps identified, this paper focuses on a Peircean structural triad for practising critical post-structural semiotics with photographs in lecturers. A study was carried out to examine how a sample of lecturers talked about photographs to consider the extent to which:

1) Semiotic meaning-making was made visible and articulated by the lecturer, and 
2) Students were invited to interrogate and engage with the photographs.

\section{Methodology}

\section{Sampling and data collection}

To establish what use lecturers make of photographs in their slide presentations, lecturer permission was obtained to video record first year undergraduate psychology lectures from an opportunistic sample of 22 lecturers at 16 universities across the UK. Recordings of one session per lecturer were made with a small video camera that was either posted to lecturers for self- recording, or used by one of the researchers attending a live lecture. The recordings captured the lecturers' visual materials, namely PowerPoint presentations, along with their speech. In total, 22 recordings were collected ranging from 35 minutes to 100 minutes in length. The lecture recordings were transcribed verbatim to present the lecturer's speech side by side with the slide that accompanied it using slide transitions as cut off points for speech sections.

The first analytical task was to investigate the extent to which photographs were used in slides. Only two lectures from the sample did not include any photographic material. Table 1 shows a breakdown of the number of slides and the number of photographs used within the 20 remaining lectures with means and standard deviations.

Table 1: Total, mean and standard deviation of slides and photographs used within the sample

\begin{tabular}{lll}
\hline & PowerPoint Slides & Photographs \\
\hline Total & 619 & 145 \\
Mean per lecture & 30.95 & 7.25 \\
Standard Deviation & 15.38 & 6.50 \\
\hline
\end{tabular}

\section{Semiotic analysis}

The second analytical goal was to identify what was the role of the photographs included in the slides in relation to lecturers' speech through examining whether the 145 
photographs were referred to and what the manner of that reference was. Only the speech that occurred whilst the photograph was displayed was used to discern the semiotic function of the photograph in a lecture.

The analysis builds on the semiotic model of meaning-making, drawing on the Peircean sign structure model of Object-Representamen-Interpretant (ORI) that involves dual Interpretant and dual Object at the intersection of image and speech content (Lackovic, 2014). Here, the photograph's Representamen was identified when the lecturer mentioned any of the elements represented in the photograph. Interpretant was considered with regard to dual interpretations of 1) whether the lecturer interpreted any photographic elements (the photographic Object-Representamen) and 2) whether a lecturer made any interpretations that link the photograph and the conceptual Object of the lecture's speech i.e. the lecture content. This semiotic model is illustrated in the Figure 2 below:

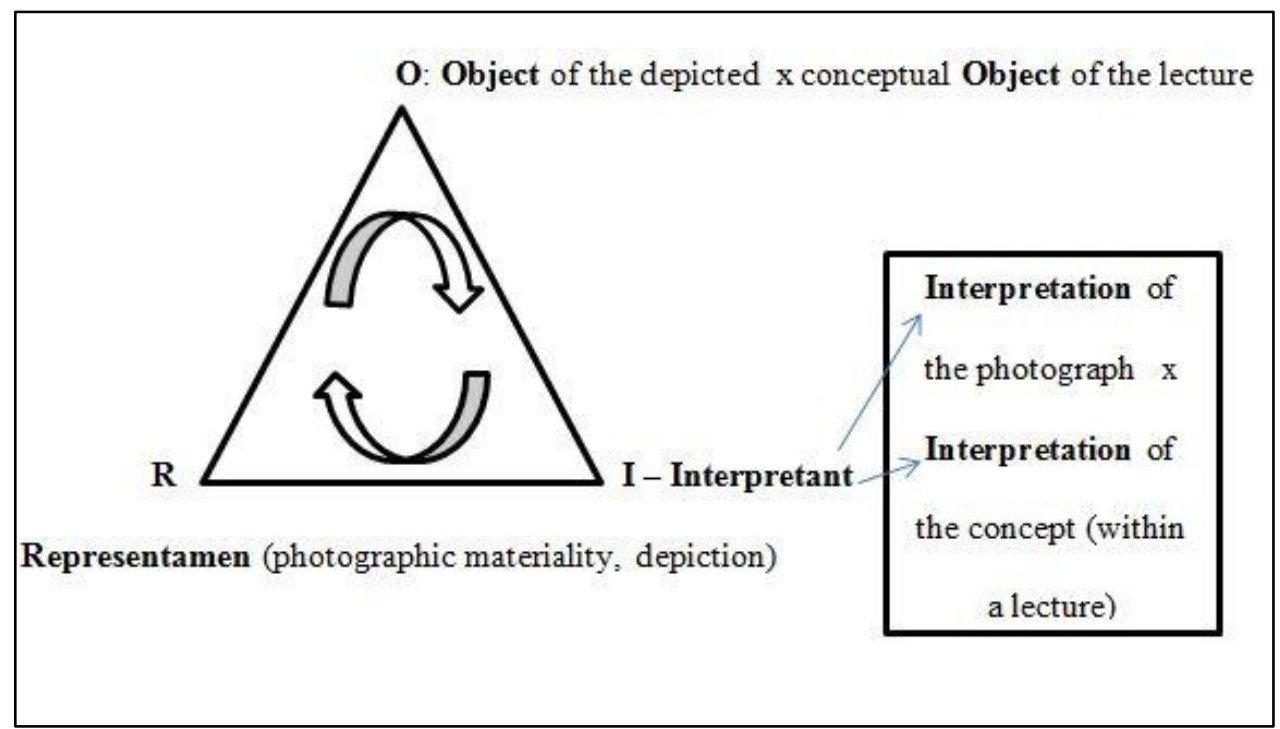

Figure 2: An analytical semiotic ORI framework (related to Figure 1) for exploring the 'voicing' of photographs related to lecture content. $x$ here means: "cross-fertilised with/brought into relation with"

The aim of the analytical coding building on Figure 2 was to identify: 
- Photographic referencing: If the lecturer referred to the photograph's ORI in any way. Here the focus is on voicing photographic Representamen. Such referencing was identified by, for example, saying 'baby' when a photograph of a baby was displayed or when a baby was one of its elements. This includes synonyms such as 'infant', 'child' and any descriptive accounts such as 'a baby is holding its parent's hand'.

- "Photograph-lecture concept" interpretation: If the lecturer presented personal interpretations of ORI and linked it to any conceptual meaning relevant to the lecture; this would mean that the speech explains the represented and its narrower and wider context of the photograph and how it relates to the slide text and/or the lecture's topic at a more encompassing level. In the baby example (above), this might mean that the lecturer explains, for instance, the importance of the baby's cute features in securing an attachment bond with its caregiver, or the evolutionary adaptations which led to this composition of features.

- "Photograph-lecture concept" inquiry: If the lecturer invited students to interpret and interrogate ORI; i.e. mentioning and exploring the author's or viewer's relation to ORI, acknowledging the student's photographic interpretation and hence interpretative multiplicity and possibilities for multiple meanings. For example, the lecturer might ask a question about a photographic feature such as how the baby's facial expression and gesturing signify attachment to the parent.

The authors negotiated codes in three rounds and separately coded the photographs and related speech. The authors are coders-insiders. This means that they are familiar with the discipline and have taught in the fields of psychology, hence were well positioned to understand what kind of relationship could a photograph and lecture 
content establish in the present sample. On the other hand, students of first year undergraduate lectures are novel to all learning resources, including photographs.

The authors and one independent coder, inexperienced in the fields of study, completed the analysis as per the distinctions above. The independent coder was provided with a randomly selected $10 \%$ of the slides that included a photograph and the coding explanations (summarised in Table 2). The coding coincided $91.66 \%$ of the time. A Kappa interrater-reliability analysis was carried out on this data to determine consistency amongst the coders. Interrater-reliability for the coders was found to be in substantial agreement; Kappa $=0.874(p<0.001)$.

It should be noted here that lecturer perspectives (interviews with lecturers) do not appear in this paper, albeit this would add a further, useful contextual dimension to the investigation. However, this article has a clear focus on identifying how photographs are referred to in situ.

\section{Outcomes}

The results point at three functional uses of photographs: Unprobed Representation, Semiotic Articulation, and Semiotic Interrogation Invitation. It is important to note that this is not a typology of photographs and their affordances per se, and the extent to which slide text referred to the photograph was not considered. Table 2 summarises the findings prior to a more elaborate presentation of findings. 
Table 2: Semiotic referencing of photographs in lecturers' speech

\begin{tabular}{|c|c|c|c|c|}
\hline Taxonomy & Subcategory & Descriptor & $\begin{array}{l}\text { Prevalence } \\
\text { in Sample }\end{array}$ & $\begin{array}{l}\text { \% of } \\
\text { sample }\end{array}$ \\
\hline \multirow[t]{2}{*}{$\begin{array}{l}\text { Unprobed } \\
\text { Representation }\end{array}$} & Attentional & $\begin{array}{l}\text { The photograph and its meanings are not } \\
\text { mentioned. The photograph might serve as } \\
\text { a (visual) metaphor for the topic in } \\
\text { question, but this is not mentioned in the } \\
\text { lecturer's speech. }\end{array}$ & 37 & $25.5 \%$ \\
\hline & Depictive & $\begin{array}{l}\text { The ORI features in speech: a } \\
\text { photographic feature(s) or meanings- } \\
\text { something that is observable in the } \\
\text { photograph or its salient feature (e.g. a } \\
\text { baby, a monkey) - is embedded in the talk } \\
\text { and content without explicitly pointing } \\
\text { at/referencing the photograph in any way. }\end{array}$ & 60 & $41.4 \%$ \\
\hline $\begin{array}{l}\text { Semiotic } \\
\text { Articulation }\end{array}$ & & $\begin{array}{l}\text { The speech articulates ORI, that is, the } \\
\text { photograph's features or the photograph } \\
\text { itself is referenced by using for example } \\
\text { "this...", "here is", "in the photo", "as you } \\
\text { can see". The speech further articulates } \\
\text { why it is relevant to a concept within the } \\
\text { lecture, providing a semiotic account of } \\
\text { the photograph's lecture-related message. }\end{array}$ & 34 & $23.4 \%$ \\
\hline $\begin{array}{l}\text { Semiotic } \\
\text { Interrogation } \\
\text { Invitation }\end{array}$ & & $\begin{array}{l}\text { The speech involves ORI interrogation } \\
\text { invitation, that is, explicitly asks for } \\
\text { students to think about the photograph } \\
\text { and/or questioning one or more or the } \\
\text { whole of the displayed feature(s) and } \\
\text { related meanings. This function might be } \\
\text { less elaborate than Articulation. }\end{array}$ & 14 & $9.7 \%$ \\
\hline Total & & & 145 & $100 \%$ \\
\hline
\end{tabular}

\section{'Unprobed' Representation}

When identified as an Unprobed Representation, the photographs could be seen as supportive of and serving as visual metaphors for the talk, providing a 'visual example' or 'illustration', but the photograph was not explicitly referenced. Either a feature is mentioned without explicitly referring to the photograph or no reference whatsoever to the photograph is made. This was the most prevalent use of photographs: occurring in the case of 97 photographs out of 145 (67\%). Two levels were identified within this function: Attentional and Depictional. 


\section{Attentional}

At the Attentional level (25.5\%), photographic meaning or features are not referenced in any way in speech, at least not obvious to the coders. This function is considered to be similar to that of Duchastel's 'attentional' category of photographs in that it is meant to capture attention, to attract the eye (Duchastel, 1978). This category also evokes Pozzer- Ardenghi and Roth's (2004) ‘decorative’ function of photographs in slides- the photograph embellishes the slide. It might be connected to lecture content or talk metaphorically. An example of this level was the inclusion, but no mention, of a photograph of a young girl ascending a dark flight of stairs whilst introducing the topic of extreme deprivation and neglect.

\section{Depictional}

The photograph is implicitly referenced at this level to represent points or content that the lecturer is talking about. An example of this might be saying 'mother and child relationship' and making a point about attachment theory whilst displaying a photograph of a woman holding a baby. The photographic content is referred to without pointing at the presence of the photograph itself. Here the ORI in the photograph is vocalised by the lecturer who provides lecture-relevant connotations linked to the photograph. There is no interpretation of photographic features or invitations for the students to interpret them. The way that this level differs from an 'attentional' level is that the photograph is integrated into the lecturer's speech- similar to Pozzer- Ardenghi and Roth's (2005) illustrative function- in order to 'depict' or 'illustrate' at least one point made in speech. This was the largest single category in the sample (41.4\%). 


\section{Semiotic Articulation}

There were cases in which the reference was explicit and went further than mentioning the interpretation (ORIs) of the photograph (23.4\%). Occasionally a lecturer foregrounded a feature by explicitly pointing it out to students and providing a commentary or synthesis of this feature or evaluation of content via the photograph. For instance, pointing out the starkness of a photograph of an infant monkey curled up at the feet of its mechanical, cloth-covered surrogate mother (e.g. Harlow \& Zimmermann, 1958), and how this (the act of curling, clutching it) represents the monkey's attachment. The lecturer is here considered to be articulating the salient features of the photograph that they wish students to attend to, as well as providing an interpretation of the photograph's meaning within the lecture context.

\section{Semiotic Interrogation Invitation}

There were a rather limited number of occasions upon which students were asked to engage with the photograph, such that they were invited to identify what it was representing. This was mostly a rhetorical question, to make a point that the students' interpretation is acknowledged and recognised rather than to elicit answers (in a lecture theatre with a large number of students, such rhetorical questions might serve the purpose of inviting students to think about the represented and relate it to their private interpretations and prior experience). Sometimes, the students were asked to provide answers and were heard providing answers. This invitation for questioning was the basis for creating a link to the lecture's content. For instance, one lecturer showed a photograph of a celebrity and another of his own house, asking students to suggest what the photographs were representing. These examples were to demonstrate that prior knowledge of an item influences their ability to name the item. Students were already familiar with the celebrity so could name him, but in relation to the photograph of the 
lecturer's house, they were only able to label it as a house, not the lecturer's house in particular. This category was a relatively uncommon occurrence (14 photographs, $9.7 \%)$.

\section{Discussion}

If one considers the potential of exploring photographs semiotically - that is, critically unpacking the photographic sign structure as per Peirce's structural sign model with regard to how a sign (ORI) functions in the culture and society - the photograph vocalisation here implies that photographs are an underused and overlooked resource in lectures. They are not used to the full extent of their semiotic potential. More than half of the presented photographs were not referred to explicitly in speech, and thus had Attentional (not being mentioned) and Depictional (serving as illustrations of the points made in talk) sub-categories under the category of 'Unprobed Representation'. Of course it is not implied here that such a functional category is not pedagogically 'good'; it can be beneficial and meaningful, signalling the demand for metaphorical and associative work from the students. However, this category does contribute to the taking of photographs, and their contribution to knowledge, for granted.

One example of a photograph being taken for granted is the above example of 'young girl ascending a dark flight of stairs'. The link between topic and photograph is unclear here - perhaps the lecturer wanted to invoke an atmosphere of foreboding, although it was a rather indirect means of doing so. The omission of a verbal explanation for this photograph might serve the purpose of leaving the student to do the interpretive work for themselves or simply positioning the photograph to 'speak for itself' or act as an embellishment. Arguably there is nothing wrong with this approach. However, it would be easy to overlook such a photograph while trying to make sense of 
both the speech with novel concepts and the slide with a photograph and text, hence losing a potentially enriching learning engagement.

In approximately $23 \%$ cases the lecturer acknowledged the photograph and pointed at a particular interpretation from the photograph as related to the lecture's content, and so deconstructing it to the students ('Semiotic Articulation'). This function is seen as useful and potentially interesting and engaging for students. Yet, the lecturer's interpretation of the photograph is foregrounded as the only and perhaps the right interpretation. This means that the Semiotic Articulation category is not without pedagogical and semiotic caveats. Foregrounding one meaning does not acknowledge multiple interpretational and contextual perspectives which constitute 'dynamic understanding of meanings' (Semetsky, 2014, p.80) as pluralistic, linked to chains of semiosis, dependent on interpreters, production and, importantly, context. In this way, some dominant, hegemonic meaning (albeit authoritative) is foregrounded and the opportunity to practice 'criticality' and dilute teacher-student power relations is missed. This phenomenon can be related to Kress and Selander's (2012) observation that there is a lack of 'the cultures of recognition' in HE in which we recognise that there are two actors and agents in the lecture's meaning-making: lecturer and student. We need to readdress and challenge what it means to be a 'sender' (lecturer) and 'receiver' (student). Lecturers are invited to view students beyond passive message recipients in 'one-way communication exercise' (Leopold, 1986, p. 15). Such a view of learning entails an understanding of the interpretational and contextual multiplicity of disciplinary concepts in HE (Lackovic, 2010; Repko, Szostak, \& Buchberger, 2013). It ultimately supports interdisciplinary views on knowledge. This approach embraces disciplinarity but initiates inter-disciplinary exploration of phenomena, thus adopting an attitude of 'critical pluralism' (Repko et al., 2013, P. 142). It must be stressed though, that the 
students' interpretations and engagement discussed here concern passive, internal student processes in line with the traditional lecturing style of the sample. However, ideally, students would be provided with the means for an active and externalised expression.

By asking students to think about what is happening in the photographs'Semiotic Interrogation Invitation'- some lecturers made a step in recognising students' meaning-making processes (Kress \& Selander, 2012). The lecturer in our 'recognition of a celebrity vs a house' example was using the strategy of inviting featural interpretation to make relevant points on the influence of our prior experience in cognitive processing. Yet, it is only at this functional level that the photographs were 'interrogated' by inviting and acknowledging more interpretations. Such interrogation invitation happened in few cases $(<10 \%)$.

Although Semiotic Articulation and Semiotic Interrogation Invitation are useful in lecture meaning-making processes, this article argues that photographs are also ideal resources to be tackled critically in lectures, in line with (social) semiotics and critical graphicacy. There was almost no trace of critical questioning of photographs, which undervalues the potential of photographs for critical thinking. To this end, another (missing) category in our taxonomy is added, the one of 'Critical Semiotic Exploration (CSE)' of photographs. CSE represents a synergy of Semiotic Articulation and Interrogation Invitation, adding critical acumen to the mix. This means that the ORI's meaning could be critically explored in relation to how signs operate in society, in the given context, another context, across meaning-making spaces, among different users and so on. This also means to consider new ways of seeing, seek new perspectives and challenge the existing ones, leading to new discoveries (Sousanis, 2015). Such a position is envisaged to support the experience of lectures becoming more 'vicarious' 
(Hodgson, 1997) in terms of engaging students' prior experience and interpretative imagination.

It is possible that one of the reasons for such a low level of Semiotic Interrogation Invitation and almost no trace of critical exploration of photographs might be the lack of recognition and knowledge of semiotics in HE. This also involves an absence of critical pedagogy with photographs and critical graphicacy. The 'old' observations on the value of those approaches in education by Sless (1981) and Roth et al. (2005) or recent observations by Schwartz and Danielson (2012), Kress and Selander (2012), Semetsky and Stables (2014) may be falling on deaf ears in HE practice and research.

The lecturer could realise more the potential of the photograph by encouraging students to inquire into its depicted features (that is paying attention to Representamen's affordances) by exploring the three places of meaning-making: production, consumption and the photograph itself (Rose, 2012). The photograph itself is the 'place' of photographic structural deconstruction that can to be related to students' experience and various socio-cultural and historical contexts and particularities. Importantly, the lecturer would be asking students to think of new interpretations and provide a critique of the photograph and the concepts it is seen to represent, by asking, for example, what is omitted/not shown in the photo and could have been shown ${ }^{2}$ ? Of course, this exercise

\footnotetext{
${ }^{2}$ For example, a photograph of a crying baby might raise the issue of the role of crying in attachment relationships, its causes and consequences; babies' cute features as contributing to parents' ability to cope with crying and total dependency; who the baby is crying for and how we know that (which can point to gender bias- is it always mother? What about single fathers?) and many other critical questions.
} 
is not always practical, or indeed necessary to do. The point made here is to suggest an increased use and awareness of photographs as semiotic resources to be explored.

If meaning-making and learning resources are acknowledged to be at the heart of any learning event, the question of why semiotics has been so marginal in HE research arises. There may be several reasons, one being that it is seen as mainly tied to linguistics or art and media studies and commonly connected to the interpretation of phenomena outside education, such as advertisement (e.g. Barthes), films, videos, books etc. Thus explorations of semiotics in relation to lectures/lecturing across HE disciplines are rare. A de Saussurean dyadic semiotic sign structure that views a sign as consisting of two entities (Signifier: the sign form, like Representamen, and Signifed: the sign meaning, like Interpretant) has been applied to understand student learning in 170 disciplinary and professional contexts (Land, Rattray, \& Vivian, 2014). Yet no studies so far have applied a Peircean sign structure model (ORI) to explore meaning-making processes with photographs in lectures, which is what the present study provides. It adds to this scarce but growing research movement on semiotics (encompassing multimodality and other related approaches) in HE practice.

The empirical focus in this paper has been on the discipline of psychology, however, this paper suggests that semiotics and related approaches need to be considered in HE research and practice across all disciplines, bringing together researchers from different backgrounds- where all participants are open-minded to different views- in order to gain greater insights and depths of meaning-making practices across disciplines (Repko et al., 2013). There are challenges to embracing semiotics in lecture pedagogy. Many pressures (e.g. research imperatives) in academia might limit the time academics spend preparing presentation slides. Yet if lecturers thought more about photographs as semiotic resources for exploration, they might 
consider choosing photographs with features salient for such an exploration, thus turning a lecture into a meaning-making event where students' interpretations are acknowledged (Kress \& Selander, 2012) and photographs are explored critically in relation to knowledge. In this way, the lecture might be more engaging not only for students but lecturers themselves.

Exploring only semiotic 'referencing' in speech is both the study's strength and limitation: whereas it provides focus, it would be useful to consider other relational nuances: for example, the reference to photographs in a slide text and photographic content affordances (different photographs have different feature salience for exploration). This study did not tackle the intentions behind the inclusion and use of photographs by the lecturers themselves, as the aim of the study was focused on investigating how photographs were used/referred to during lectures. An investigation of lecturers' intentions in terms of lecture objectives and design is seen as the next logical step in studying the use of semiotic interrogations in lectures, yet, it is beyond the scope of this paper. Thus this paper opens up more questions and possibilities for future explorations: are lecturers' relationships to knowledge and attitudes to lecturing linked to their use of photographs and how? What is lecturers' intention behind including a photograph in a slide? Would lecturers' exploration of the semiotic potential of photographs bring a better lecture experience to students? Would it have an effect on students' engagement with the images in general?

\section{Critical Semiotic Exploration (CSE): practical application}

We have presented an interpretative semiotic model (Figure 1) that lecturers could adopt in their practice and adapt to their teaching-learning needs and goals. Here this is expanded with some practical possibilities of critical semiotic exploration (CSE). 
The following questions exemplify how lecturers could apply CSE of a photograph that, for example, represents humans and their acts, considering both the representational qualities and ideas as well as what kind of relationship the photograph puts the viewers into:

- Why has the photograph been included on the slide/ in the lecture?

- How would the meaning of the photograph change in different university, within a different discipline, and national/international contexts?

- What actors might be behind this photograph apart from the ones possible to be seen, if any?

- What do/can we know about the provenance of the photograph?

- Who can you see in the picture - what gender, what cultural or ethnic origin, what social status?

- What details/objects/actions can you see in the picture?

- Choose another context and think of another type of viewer (different profession, beliefs, etc.) - how could these changes affect interpretation of what we see?

- What socio-cultural and experiential factors influence your interpretation?

- How do you personally relate to this picture and what it depicts?

- What are the conditions for the depicted activity to occur and why?

- What is the result or consequence of the depicted activity and why?

- Can we assess how this photograph claims the "truth"? 
The above questions are only examples of many possible questions. Examples are made to help illustrate semiotic interrogation possibilities. It is neither possible to ask so many questions nor would it be a practical thing to do in a single lecture -these are possibilities which can be chosen and modified in accordance with a lecturer's pedagogical preference and aims.

Ideally, this CSE would look different in every lecturing situation, as different topics and different photographs lend themselves to different questions. For instance, Maxwell (2007) describes a situation where history students are asked questions on a photograph to consider what it might mean to be both a prisoner and a soldier in WW2 and how they both might be feeling about the situation, touching upon wider humanistic consequences of war and what it means to be human. Mitchell (2002) describes another scenario of visual exploration in which the class is asked to question everything they see as they are newly "ignorant" of the use of their visual organs, which necessarily involves invoking a semiotic interrogation as they try to work out what it is they are seeing through the use of their prior experiences. In large classrooms where such active engagement may not be feasible, lecturers can engage students' thinking via questioning that might open up avenues of interrogation in each individual student. CSE activities could be a useful exercise for students' projects and assignments for example.

In order to support lecturers' ability and willingness to include CSE in their lectures, academic developers could help teaching staff by inviting experts in semiotics to give seminars/training. Explanations and practical suggestions here and in related publications are also sufficient for opening up staff semiotic awareness.

\section{Conclusion}

How are photographs vocalised in lectures? The semiotic taxonomy of photographic vocalisation developed here suggests that the vast majority of 145 
photographs (67\%) in 20 PowerPoint presentations act either as speech content 'illustrations' in lecturers' talk (41.4\%) or were not vocalised at all (25.5\%). There are some cases when the lecturers' talk explicitly connected the photograph, its features and the lecture's content (23.4\%) and only few cases when the students were invited to think about the photographs prior to the lecturer's interpretation $(9.7 \%)$. It is neither argued here that any category of photograph semiotic vocalisation is bad nor that every single photograph needs to be semiotically interpreted as if this practice is always desirable or applicable. Rather, the argument is that the semiotic potential of the photographs in lectures is underused. The study shows the extent to which photographs are not talked about in lectures, hence establishing a need to consider the opportunities for learning that might arise if more photographs are treated as semiotic resources to be discussed.

Furthermore, photographs are by and large not tackled critically as particular representations of the world, although there is evidence that photographs and media disseminated imagery can govern and even distort our sense of the world and 'reality' (Apple, 2013). Future research could explore related lecturers' and students' attitudes, opinions and knowledge development through photograph exploration.

The practical implications of this paper's outcomes would be to motivate an introduction of 'semiotic' seminars or similar (Whitley, 2013) for HE practitioners in order to raise awareness of the photographic potential in lectures.

Finally, to answer the question posed in the title: perhaps a photograph is worth a thousand words and it can support meaning-making when left unvoiced. However, it will not 'tell' us much and certainly it will not 'speak' critically in a lecture if it is taken for granted, if it privileges only one interpretation (lecturer's), and if it is left unquestioned. 


\section{References}

Apple, M. W. (2013). Education and power: Routledge.

Ausubel, D. P. (1978). In defense of advance organizers: A reply to the critics. Review of Educational Research, 48(2), 251-257.

Barthes, R. (1977). Image-Music-Text, ed. and trans (Vol. 332). S. Heath, London: Fontana.

Barthes, R. (1981). Camera lucida: Reflections on photography: Macmillan.

Bateman, J. (2014). Text and image: A critical introduction to the visual/verbal divide: Routledge.

Bligh, B., \& Lorenz, K. (2010). The rhetoric of multi-display learning spaces: exploratory experiences in visual art disciplines. Seminar.net - International journal of media, technology and lifelong learning, 6(1), 7-27.

Cantor, R. M. (2000). Foundations of Roentgen semiotics. Semiotica, 131(1-2), 1-18.

Duchastel, P. C. (1978). Illustrating instructional texts. Educational Technology, 18(11), 36-39.

Exley, K., \& Dennick, R. (2004). Giving a lecture: From presenting to teaching. London: RoutledgeFalmer.

Fiske, J. (2010). Introduction to communication studies. London: Routledge.

Gabriel, Y. (2008). Against the tyranny of PowerPoint: Technology-in-use and technology abuse. Organization Studies, 29(2), 255.

Harlow, H. F., \& Zimmermann, R. R. (1958). The development of affectional responses in infant monkeys. Proceedings of the American Philosophical Society, 102(5), 501-509.

Hodge, R., \& Kress, G. R. (1988). Social semiotics. Cambridge: Polity.

Hodgson, V. (1997). Lectures and the experience of relevance. The Experience of Relevance. Edinburgh: Scottish Academic Press.

Kjeldsen, J., E. (2006). The rhetoric of PowerPoint. Seminar.net - International journal of media, technology and lifelong learning, 2(1), 1-17.

Kress, G., \& selander, S. (2012). Multimodal design, learning and cultures of recognition. Internet and Higher Education, 15(4), 265-268.

Lackovic, N. (2010). Creating and reading images: towards a communication framework for Higher Education learning. Seminar. net: International Journal of Media, Technology and Lifelong Learning.

Lackovic, N. (2014). An image based concept inquiry (IBCI) scenario applied within higher education. (PhD thesis), University of Nottingham.

Land, R., Rattray, J., \& Vivian, P. (2014). Learning in the liminal space: a semiotic approach to threshold concepts. Higher Education, 67(2), 199-217.

Leopold, K. (1986). Nonverbal communication in lecturing: A Constructivist perspective. Higher Education Research and Development, 5(1), 15-29.

Maxwell, A. (2007). Ban the Bullet-point! Content based PowerPoint for Historians. The History Teacher, 41(1), 39-54.

Mitchell, W, J, T. (2002) Showing Seeing: a critique of visual culture. Journal of Visual Culture, 1(165), (165-182).

Mulligan, D., \& Kirkpatrick, A. (2000). How much do they understand? Lectures, students and comprehension. Higher Education Research and Development, 19(3), 311-335.

Nellhaus, T. (1998). Signs, social ontology, and critical realism. Journal for the Theory of Social Behaviour, 28(1), 1-24.

Nelson, R. S. (2000). The slide lecture, or the work of art "History" in the age of mechanical reproduction. Critical Inquiry, 26(3), 414-434. 
Pozzer- Ardenghi, L., \& Roth, W. (2005). Making sense of photographs. Science education, 89(2), 219-241.

Pozzer-Ardenghi, L., \& Roth, W.-M. (2004). Photographs in lectures: Gestures as meaning-making resources. Linguistics and education, 15(3), 275-293.

Pozzer, L., \& Roth, W.-M. (2003). Prevalence, function, and structure of photographs in high school biology textbooks. Journal of Research in Science Teaching, 40(10), 1089-1114. doi:10.1002/tea.10122

Repko, A., F, Szostak, R., \& Buchberger, M., P. (2013). Introduction to interdisciplinary studies (1st Edition ed.). Los Angeles, California: SAGE Publications, Inc.

Rose, G. (2012). Visual methodologies: An introduction to researching with visual materials. London: Sage.

Roth, W.-M., Pozzer-Ardenghi, L., \& Han, J. Y. (2005). Critical graphicacy: Understanding visual representation practices in school science (Vol. 26). Dordrecht, The Netherlands: Springer Science \& Business Media.

Rowley-Jolivet, E. (2002). Visual discourse in scientific conference papers A genrebased study. English for specific purposes, 21(1), 19-40.

Schwartz, N., \& Danielson, R. (2012). What kind of graphic is this? A framework for delineating the graphics in text-graphic research. Paper presented at the Keynote address presented to the Special Interest Group" Learning with Text and Graphics" at the bi-annual meeting of the European Association for Research on Learning and Instruction, Grenoble, France, Grenoble, France.

Semetsky, I., \& Stables, A. (2014). Pedagogy and edusemiotics: Theoretical challenges/practical opportunities (Vol. 62): Springer.

Sless, D. (1981). Learning and visual communication. London: Croom Helm.

Slykhuis, D. A., Wiebe, E. N., \& Annetta, L. A. (2005). Eye-tracking students' attention to PowerPoint photographs in a science education setting. Journal of Science Education and Technology, 14(5-6), 509-520.

Sousanis, N. (2015). Unflattening: Harvard University Press.

Whitley, C. T. (2013). A picture is worth a thousand words: Applying image-based learning to course design. Teaching Sociology, 41(2), 188-198. 